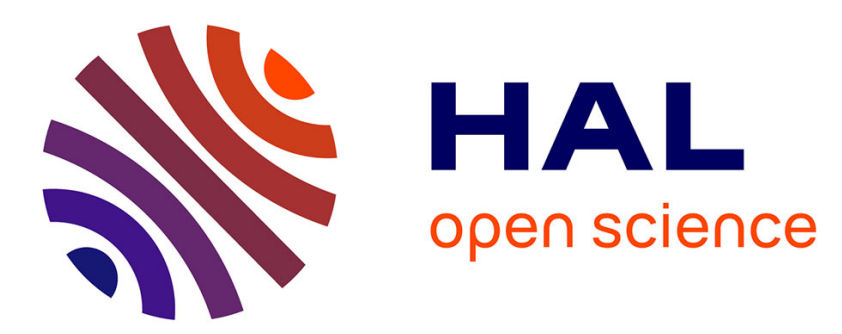

\title{
Prioritizing the provision of urban ecosystem services in deprived areas, a question of environmental justice
}

Wissal Selmi, Slaheddine Selmi, Jacques Teller, Christiane Weber, Emmanuel

Léo Riviere, David Nowak

\section{- To cite this version:}

Wissal Selmi, Slaheddine Selmi, Jacques Teller, Christiane Weber, Emmanuel Léo Riviere, et al.. Prioritizing the provision of urban ecosystem services in deprived areas, a question of environmental justice. AMBIO: A Journal of the Human Environment, 2020, 10.1007/s13280-020-01438-1 . hal03030612

\section{HAL Id: hal-03030612 \\ https://hal.science/hal-03030612}

Submitted on 30 Nov 2020

HAL is a multi-disciplinary open access archive for the deposit and dissemination of scientific research documents, whether they are published or not. The documents may come from teaching and research institutions in France or abroad, or from public or private research centers.
L'archive ouverte pluridisciplinaire HAL, est destinée au dépôt et à la diffusion de documents scientifiques de niveau recherche, publiés ou non, émanant des établissements d'enseignement et de recherche français ou étrangers, des laboratoires publics ou privés. 
Preprint, the final version, of the article that has been transferred to the journal's production team.

To cite this article: Selmi, W., Selmi, S., Teller, J. Weber, C., Rivière, N., Nowak, D. Prioritizing the provision of urban ecosystem services in deprived areas, a question of environmental justice. Ambio (2020). https://doi.org/10.1007/s13280-020-01438-1

Prioritizing the provision of urban ecosystem services in deprived areas, a question of environmental justice

\begin{abstract}
The distribution of urban ecosystem services (UES) is often uneven across socioeconomic groups, leading to environmental justice issues. Understanding the distribution of UES across a landscape can help managers ensure an equitable distribution of services. While many past studies have focused on the distribution of green spaces in relation to socioeconomic variables, this research analyzes the distribution of UES provided by these green spaces. This research quantified air pollution removal, atmospheric carbon reduction, and surface runoff mitigation provided by urban trees in Strasbourg city (France). The provision of these three UES was studied at the census block scale by creating an index of UES delivery, which was contrasted with a constructed social deprivation index. Our results show that there is no significant association between the delivery of UES and social deprivation. Some deprived populations benefit from high UES delivery. Results also suggest that mapping associations between UES delivery and social deprivation should be integrated with future development plans to enhance the equitable distribution of UES. This study provides insights into the French context where studies about the distribution of UES at a small-area level remain lacking.
\end{abstract}

Keywords: Deprivation, Environmental justice, Urban ecosystem services, Urban trees 


\section{Introduction}

Numerous studies have stressed the importance of quantifying urban ecosystem services (UES) at different scales and integrating them into decision-making processes (Ernstson et al. 2010; Kremer et al. 2016; Yang et al. 2018). However, while the concept of UES represents a bridge between social and ecological systems within a city, little is known about the relationship between social systems and ecosystem services delivery at the local level (Amini Parsa et al. 2019). This issue is increasingly addressed within the environmental justice (EJ) framework, given the recognition of urban green spaces (UGS) and their UES as local solutions to both local (e.g. air pollution, intense precipitation events) and global environmental burdens (e.g. climate change) (Zhao and Sander. 2015; Amini Parsa et al. 2019; Escobedo et al. 2019) and the growing conviction that uneven exposure to environmental burdens and benefits among social groups affects city sustainability (Baró et al. 2019). The concept of EJ was mainly developed in the USA in the 1970s, with a focus on the relationship between socioeconomic groups and the distribution of environmental burdens and benefits, assuming that disadvantaged communities are most exposed to environmental risks (Greenberg and Cidon. 1997; Agyeman et al. 2002; Kruize et al. 2007; Brown et al. 2012; Raddatz and Mennis. 2013; Boyce et al. 2016). The application of EJ framework to UES focuses on their immediate distribution at the local scale (e.g. city-scale, block group, neighborhood) where ecosystem services delivery and benefits are realized (Baró et al. 2019) and hence can support policies of sustainability to maintain their long-term production in a fair and just manner (de Groot et al. 2010; Boone and Fragkias. 2013). An important scientific corpus has been constructed around environmental justice linked to UGS (Grove et al. 2006; Heynen et al. 2006; Pham et al. 2012). For example, the distribution of green cover in Edinburgh, Glasgow, Leicester, Oxford and Sheffield (UK) and San Juan 
(Puerto Rico) has been found to be linked with urban characteristics like housing type, detached housing and age of construction (Tratalos et al. 2007; Martinuzzi et al. 2018). In Terre Haute (IN, USA), positive correlations were found between leaf area, population density, and median income (Jensen et al. 2005). However, knowledge about the distribution of UES from an EJ perspective remains limited (Wilkerson et al. 2018; Baró et al. 2019). For instance, few studies have investigated the link between income level and temperature reduction (Jenerette et al. 2011), and the variation of amenities according to economic status and ethnic origin (Landry and Chakraborty. 2009). Dobbs et al. (2014) found that UES provision in Melbourne (Australia) was positively related to the degree of human development, assessed as the ratio between education level and income. In Bogota (Colombia), Escobedo et al. (2015) found that the wealthiest population had the greatest access to particulate matter removal by trees. In Europe, EJ applied to UES is an emerging subject that has been investigated only in few urban areas, notably Berlin (Lakes et al. 2014), Barcelona (Baró et al. 2016; Baró et al. 2019) and Porto (Graça et al. 2017).

In France, investigations of UES within the EJ framework are rather scarce. Cohen et al. (2012) assessed indirectly UES distribution in Paris through perception and species indicators. In 2013, the national program of ecosystem functions and services assessment ("L'évaluation française des écosystèmes et des services écosystémiques": EFESE) was launched. It addressed the disparity in the distribution of green spaces in French cities by referring to some indicators like accessibility and attendance (EFESE 2018). However, the distribution of UES across a socioeconomic gradient has not been considered.

In line with such evidence, it is essential to investigate more case studies to draw a more complete and general picture about the interactions between socioeconomic factors and ecosystem services depending on local contexts. Providing empirical research about how socioeconomic factors influence ecosystem services can enrich research in this field. It may 
also facilitate orienting urban planning toward increased sustainability and equity. Hence, our paper contributes to the literature of environmental justice related to UES by providing a case study combining biophysical indicators that directly measure urban ecosystem services and socioeconomic indicators in a context of French cities.

Therefore, the main goal of this study is to conduct a quantitative assessment of UES from a distributive justice perspective in Strasbourg city (France) and analyze if there are socialspatial inequalities related to their provision. Distributive justice of ES is defined as the equal access to ES among different social groups (Sievers-Glotzbach 2013; Schüle et al. 2019).

We focused on ecosystem services provided by trees located in public green spaces and along streets as these areas are managed via public funding. We aimed to analyze the distribution of UES delivery across a deprivation gradient defined by both social and material disadvantages of local communities (Havard et al. 2008). Our study had three specific objectives: 1) identify and assess socioeconomic variables that define deprivation, 2) quantify three UES (air purification, runoff mitigation, atmospheric carbon reduction) and combine them into one UES delivery index, and 3) investigate the relationship between social deprivation and UES delivery to highlight potential environmental inequalities within the city.

\section{Methods}

\subsection{Study area}

This study was conducted in Strasbourg city, in Northeastern France $\left(48^{\circ} 35^{\prime} \mathrm{N}\right.$ and $\left.7^{\circ} 45^{\prime} \mathrm{W}\right)$. The city covers an area of 7830 ha and supports about 275700 inhabitants with a population density of 35 inhabitants per ha (INSEE, 2016). The city is covered by 400 ha of parks and about 1600 ha of protected alluvial forests that are major carbon sinks in the city. The historic core of the city is surrounded by the green belt which is $650 \mathrm{~m}$ wide and supports 370 ha of gardens, vacant areas, and green spaces. Strasbourg occupies the $7^{\text {th }}$ place in terms of 
number of $\mathrm{m}^{2}$ of tree cover per inhabitant ( $32 \mathrm{~m}^{2}$ /inhabitant) while the first place is occupied by Montpellier city (43 $\mathrm{m}^{2}$ of tree cover / inhabitant; about 5700 ha; 268456 inhabitants,).

Strasbourg is projected to develop more than 1000 ha of green and vacant spaces between 2017 and 2030. This development would lead to the release of carbon stored in soils and vegetation and weaken strategies for mitigating climate change. Increasing cumulative rainfall along with substantial impervious surfaces and a dense hydrographic network makes the city vulnerable to flooding (ADEUS 2018). Air pollution is also an environmental burden in Strasbourg, as $\mathrm{NO}_{2}$ exposure is increasing and $\mathrm{PM}_{10}$ exceeds prescribed daily limits (Atmo Grand-Est 2018).

The city contains 14 neighborhoods subdivided into 116 census blocks called IRIS (Fig.1a). To ensure relevant analysis of social and ecological mismatches in Strasbourg, IRISs with a limited population (less than 250 inhabitants) were excluded. According to Havard et al. (2008), the excluded blocks with very low population numbers do not present sufficient socioeconomic information. In total, 94 IRISs were included in our study sample. The average population per IRIS was 2619 inhabitants with a mean IRIS area of 59 ha (44 inhabitants per ha).

\subsection{Quantification of social deprivation}

Studies of UES from an EJ perspective are often based on literature reviews to select socioeconomic variables to define social deprivation (e.g. McPhearson et al. 2013; Dobbs et al. 2014; Baró et al. 2019). In this work, we instead built a composite deprivation index based on quantitative data and statistical analyses.

Data on socioeconomic variables that are often used to reflect social deprivation within UES environmental justice frameworks (e.g. Pham et al. 2012; Cohen et al. 2012; McPhearson et al. 2013; Graça et al. 2018) were obtained from the 2013 national census (INSEE 2016). 
From these original data, eight socioeconomic variables providing inter-related indicators of social deprivation were determined: (1) Median household income (in euros), (2) Density of household with standard of living below poverty line (= number of household with standard of living below poverty line / IRIS area in ha), (3) Density of rent-controlled housing (HLM) (= number of HLM / IRIS area in ha), (4) proportion of immigrants in the population (= number of immigrants / total number of IRIS inhabitants), (5) ratio of house owners to tenants $(=$ number of owner-occupied primary residences / number of non-owner occupied primary residences), (6) ratio of unemployed to active people (= number of unemployed people aged 15 and older / number of employed people aged 15 and older), (7) ratio of blue collar to white collar (number of blue collar workers aged 15 and older / number of white collar workers aged 15 and older), and (8) ratio of households without car to households with cars (= number of households without a car / number of households with a car).

\subsection{Quantification of UGS and UES}

Three UES provided by public urban trees were selected: atmospheric carbon reduction, surface runoff mitigation, and air pollution removal. The three UES are considered as the most important in terms of distributional EJ (Amini Parsa et al. 2019; Baró et al. 2019). While production and benefits of surface runoff mitigation and air pollution removal are mostly local effects, atmospheric carbon reduction affects global climate regulation (Fisher et al. 2009). Numerous other local urban ecosystem services that impact human well-being are affected by local leaf area and biomass, such as building energy use and thermal comfort (Graça et al. 2018). Although it affects global climate regulation, it is of interest to study the carbon storage and sequestration by trees in urban areas since they are more vulnerable to climate change and where adaptation strategies should be developed (Amini Parsa et al. 2019). Producing 
information about the distribution of this UES may contribute to enhanced climate justice even at the local scale (Srang-iam 2011).

The three UES were assessed using i-Tree Eco model that provides information about forest structure and benefits (Nowak et al. 2008; www.itreetools.org). i-Tree Eco guidelines (iTree Eco User's Manual 2013) were followed to define the sample size and field survey protocol to collect municipal urban forest data. The sampling design and data collection were carried out by delimiting and stratifying public UGS within land-use classes, assessing tree cover within public UGS, generating field samples, and collecting field data

The city and its public green spaces were stratified into 8 land-use classes based on 1:10000 land-cover database of the Alsace region provided for 2008 by the "Cooperation for Geographic Information System in Alsace', (CIGAL). Using the 2010 map of public green spaces provided the City Council of Strasbourg (EMS), 228 circular 11 m-radius plots (0.04 ha) were selected. Study plots were distributed randomly within public green spaces using random plot generation functionality of Arcgis (by generating $\mathrm{x}$ and $\mathrm{y}$ coordinates) and following the model documentation (see Selmi et al. 2016).

The field survey was conducted during the leaf-on season of 2013. At each plot, general information (date, plot address, GPS coordinates, land use, tree and shrub cover, ground cover and plantable space) were recorded, as well as individual tree data (species, diameter at breast height (DBH), total tree height, crown width, height to base of live crown, crown light exposure, crown dieback percent, percent crown missing).

Local hourly pollution data were obtained from the regional Air Quality Agency (AtmoEst). These data were measured at six monitoring stations located within the study area over a one-year period (from July 2012 to June 2013). Concentrations of carbon monoxide (CO), nitrogen dioxide $\left(\mathrm{NO}_{2}\right)$, sulfur dioxide $\left(\mathrm{SO}_{2}\right)$, ground-level ozone $\left(\mathrm{O}_{3}\right)$, particulate matter of 
less than $2.5 \mu \mathrm{m}\left(\mathrm{PM}_{2.5}\right)$ and particulate matter between $2.5 \mu \mathrm{m}$ and $10 \mu \mathrm{m}\left(\mathrm{PM}_{10}\right.$ coarse $)$ were

150

151

152

153

calculated as averages values from the six monitoring stations. Weather data (wind speed, precipitation, temperature, etc.) were retrieved from "Météo France" (two stations within the study area) and one station of the National Oceanic and Atmospheric Administration (NOAA) located at Strasbourg city.

The collected field and environmental data were combined in i-Tree Eco v5 to assess basic structural information (e.g., tree density, species composition) and three UES: air purification (dry deposition indicator), atmospheric carbon reduction (carbon storage and sequestration indicators) and surface runoff mitigation (avoided runoff indicator). The average rates of all UES per tree cover (i.e., $\mathrm{g} \mathrm{m}^{-2}$ or $\mathrm{m}^{3} \mathrm{~m}^{-2}$ ) were calculated for each land-use class. Following UES environmental justice literature (Dobbs et al. 2014; McPhearson et al. 2013; Baró et al. 2019), the aggregated index was calculated to quantify UES at each IRIS following the formula:

UESi $(\mathrm{g})($ IRIS scale $)=\sum$ (tree cover per land-use class $\mathrm{j}\left(\mathrm{m}^{2}\right) \times$ Average of $\mathrm{UES}_{\mathrm{i}}$ per tree cover per land-use class $\mathrm{j}\left(\mathrm{g} \mathrm{m}^{-2}\right.$ or $\left.\mathrm{m}^{3} \mathrm{~m}^{-2}\right)$ ). The IRIS value was then divided by the area of the corresponding IRIS to obtain a relative measure of that UES metric (UES $\mathrm{m}^{-2}$ ).

\subsection{Statistical analysis}

Separate Principal Component Analyses (PCA) were conducted on the three sets of variables (socioeconomic, UGS, and UES) to summarize the original variables into a few components. Only components with eigenvalues exceeding 1 were retained (Vyas and Kumaranayake 2006). PCA provided three composite indices of social deprivation, UGS parameters and, UES delivery (see results). 

indices to identify vulnerable areas (i.e. areas with high deprivation and low UES delivery). The three classes (high, moderate and low) were identified based on the mean of UES and deprivation indices $\pm 1 / 2$ standard deviation (Faburel et Guymard 2008). The combination of deprivation and UES classifications provided nine categories that were mapped using Geographic Information using Esri's ArcGIS for Desktop 10.5.

Since study units were locations, spatial autocorrelation, and hence statistical nonindependence among observations (Legendre and Legendre 1998; Rangel et al. 2006) could occur. Spatial autocorrelation among indices of deprivation, UGS parameters, and UES delivery was checked for using Moran's correlograms (Legendre and Legendre 1998). The studied IRISs were organized into 10 equifrequent classes of geographic distance, with a lag ranging from 0.527 to $2.897 \mathrm{~km}$ and sample size of 872 pairs of IRISs per class. For each distance class, a Moran's I autocorrelation coefficient was calculated and tested for significance using 999 permutations. A correlogram was then obtained by plotting the Moran's I values against the upper boundaries of the corresponding distance classes, and the significance of the whole correlogram was assessed by applying the Bonferroni correction for multiple tests (Legendre and Legendre 1998). These spatial autocorrelation analyses were carried out using SAM software 4.0 (Rangel et al. 2006).

The significance of social deprivation as a predictor of green space cover and UES delivery was investigated using simple linear regressions. These regressions were performed using Ordinary Least Square (OLS) models assuming independence among model residuals. Spatial models were also run that considered model residuals as correlated and their covariance as a function of the geographic distance between pairs of sites; Generalized Least Square (GLS) models (Cressie 1993; Rangel et al. 2006). The competing non-spatial and spatial models were then compared according to their AICc (Akaike Information Criteria corrected for small sample 
size) and $\mathrm{R}^{2}$. The best model was the one having the lowest AICc and highest $\mathrm{R}^{2}$ values (Rangel et al. 2006). These regression analyses were performed using SAM software 4.0 (Rangel et al. 2006).

\section{Results}

\subsection{General results about social deprivation and UES delivery}

The first component extracted from a PCA on the original socioeconomic variables has an eigenvalue of 5.26 and explains $66 \%$ of the variance of the original data set, corresponding to an increasing axis of social deprivation (Table 1). However, the second component has an eigenvalue less than $1(0.79)$ and is not retained.

Twenty-eight IRISs are characterized as having the best living condition, where only $12 \%$ of households live below the poverty line, $88 \%$ of the population has a job and only $4 \%$ of houses are rent-controlled. Conversely, the high deprivation class contains 33 IRISs that are characterized by a high average of households who live below the poverty line (38\%) and a high percentage of immigrants $(47 \%)$.

Descriptive statistics of UGS and UES parameters for the 94 IRIS are shown in Table 1. Average green spaces cover and tree cover across all IRIS are $14.7 \%$ and $5.7 \%$ respectively. Average species number and tree density are 114 species and 23 trees ha- ${ }^{-1}$ respectively. The conducted PCA reduces UGS variables into one component accounting for $75 \%$ of the variance (eigenvalue $=3.02$ ), while the second component has an eigenvalue of 0.73 . The first component is positively correlated with all original variables, thus providing a composite index of UGS characteristics (Table 1).

UES provided by public urban trees in Strasbourg city during 2013 are estimated to $128000 \mathrm{t}$ and $4000 \mathrm{~kg} \mathrm{C}$ year ${ }^{-1}$ of stored and sequestered carbon respectively, $88 \mathrm{t}^{\text {year }}{ }^{-1}$ of removed air pollutants including $1.2 \mathrm{t}_{\text {year }}^{-1}$ of $\mathrm{CO}, 13.8 \mathrm{t}_{\text {year }}^{-1}$ of $\mathrm{NO}_{2}, 55.9 \mathrm{t}_{\text {year }}^{-1}$ of $\mathrm{O}_{3}$; 11.8 t year $^{-1}$ of $\mathrm{PM}_{10}, 4.5 \mathrm{t}_{\text {year }}{ }^{-1}$ of $\mathrm{PM}_{2.5}$ and 1.0 t year $^{-1}$ of $\mathrm{SO}_{2}$ (Note: $\mathrm{PM}_{10}$ estimates exclude 
$223 \mathrm{PM}_{2.5}$ particles) and $24160 \mathrm{~m}^{3}$ year $^{-1}$ of avoided runoff. A PCA summarizes the investigated 224 UES into a single composite index (first component) that explains $99 \%$ of the total variance 225 and has an eigenvalue of 8.92. In contrast, the second component has an eigenvalue of 0.07. 226 The composite index derived from this PCA is positively correlated with all original variables 227 (Table 1), indicating that high scores correspond to areas with increased delivery of UES. 
Table 1. List of assessed socioeconomic, green space and ecosystem service variables among IRISs, with descriptive statistics and correlations (Pearson correlation coefficient) with the indices derived from the Principal Component Analyses (sample size = 94 IRIS).

\begin{tabular}{|c|c|c|c|c|c|c|c|}
\hline & & \multirow[t]{2}{*}{ Variables } & \multirow[t]{2}{*}{ Range } & \multirow[t]{2}{*}{ Mean \pm SD } & \multicolumn{2}{|c|}{ Correlation test } & \multirow[t]{2}{*}{$\begin{array}{l}\text { Constructed } \\
\text { index }\end{array}$} \\
\hline & & & & & $\boldsymbol{r}$ & $\boldsymbol{P}$ & \\
\hline \multirow{8}{*}{\multicolumn{2}{|c|}{ Socio-economic variables }} & Median household income (euros) & $10847-38,290$ & $19228 \pm 5495$ & -0.799 & $<0.0001$ & \multirow{8}{*}{$\begin{array}{l}\text { Deprivation } \\
\text { index }\end{array}$} \\
\hline & & $\begin{array}{l}\text { Density of household with standard of living below poverty } \\
\text { line (number } \mathrm{ha}^{-1} \text { ) }\end{array}$ & $0-0.04$ & $0.01 \pm 0.01$ & 0.941 & $<0.0001$ & \\
\hline & & Density of rent-controlled housing (HLM) (number ha $\left.{ }^{-1}\right)$ & $0-89.61$ & $10.89 \pm 16.01$ & 0.730 & $<0.0001$ & \\
\hline & & Proportion of immigrants in the population & $0.05-0.40$ & $0.20 \pm 0.08$ & 0.808 & $<0.0001$ & \\
\hline & & Ratio of house owners to tenants & $0-3.99$ & $0.53 \pm 0.59$ & -0.575 & $<0.0001$ & \\
\hline & & Ratio of unemployed to active people & $0.06-0.95$ & $0.27 \pm 0.18$ & 0.916 & $<0.0001$ & \\
\hline & & Ratio of blue collar to white collar & $0.05-60.68$ & $4.38 \pm 9.19$ & 0.765 & $<0.0001$ & \\
\hline & & Ratio of households without car to households with cars & $1.25-7.14$ & $2.49 \pm 0.99$ & 0.893 & $<0.0001$ & \\
\hline \multirow{4}{*}{\multicolumn{2}{|c|}{ UGS variables }} & Cover of green areas $(\%)$ & $0-68.30$ & $16.80 \pm 15.30$ & 0.917 & $<0.0001$ & \multirow{4}{*}{$\begin{array}{l}\text { Urban } \\
\text { vegetation index }\end{array}$} \\
\hline & & Number of species & $17-671$ & $114 \pm 108$ & 0.602 & $<0.0001$ & \\
\hline & & Tree density (trees ha $\left.{ }^{-1}\right)$ & $0.25-182.29$ & $23.22 \pm 27.77$ & 0.941 & $<0.0001$ & \\
\hline & & Tree cover $(\%)$ & $0-44$ & $5.70 \pm 7.50$ & 0.962 & $<0.0001$ & \\
\hline \multirow{9}{*}{$\begin{array}{l}\text { UES } \\
\text { variables }\end{array}$} & Atmospheric & Carbon storage $\left(\mathrm{kg} \mathrm{ha}^{-1}\right)$ & $0.32-36058$ & $7160 \pm 8195$ & 0.994 & $<0.0001$ & \multirow{9}{*}{$\begin{array}{l}\text { Ecosystem } \\
\text { services delivery } \\
\text { index }\end{array}$} \\
\hline & carbon reduction & Carbon sequestration $\left(\mathrm{kg} \mathrm{ha}^{-1} \mathrm{year}^{-1}\right)$ & $0.01-1126$ & $203 \pm 230$ & 0.976 & $<0.0001$ & \\
\hline & $\begin{array}{l}\text { Surface runoff } \\
\text { mitigation }\end{array}$ & Avoided runoff $\left(\mathrm{m}^{3} \mathrm{ha}^{-1}\right)$ & $0-9.76$ & $1.54 \pm 1.85$ & 0.994 & $<0.0001$ & \\
\hline & \multirow{6}{*}{ Air purification } & CO removal $\left(\mathrm{g} \mathrm{ha}^{-1}\right)$ & $0-447$ & $79 \pm 91$ & 0.999 & $<0.0001$ & \\
\hline & & $\mathrm{NO}_{2}$ removal $\left(\mathrm{g} \mathrm{ha}^{-1}\right)$ & $0-5146$ & $912 \pm 1047$ & 0.999 & $<0.0001$ & \\
\hline & & $\mathrm{O}_{3}$ removal $\left(\mathrm{g} \mathrm{ha}^{-1}\right)$ & $0-20774$ & $3682 \pm 4226$ & 0.999 & $<0.0001$ & \\
\hline & & $\mathrm{PM}_{10}$ removal $\left(\mathrm{g} \mathrm{ha}^{-1}\right)$ & $0-4374$ & $775 \pm 890$ & 0.999 & $<0.0001$ & \\
\hline & & $\mathrm{PM}_{2.5}$ removal $\left(\mathrm{g} \mathrm{ha}^{-1}\right)$ & $0-1676$ & $297 \pm 341$ & 0.999 & $<0.0001$ & \\
\hline & & $\mathrm{SO}_{2}$ removal $\left(\mathrm{g} \mathrm{ha}^{-1}\right)$ & $0-385$ & $68 \pm 78$ & 0.999 & $<0.0001$ & \\
\hline
\end{tabular}



green spaces are concentrated in these 24 IRISs. IRISs with high UES delivery produce about $88 \%$ of the total amount of UES in Strasbourg followed by IRISs with moderate delivery (10\%) and low delivery (2\%). Relative UES delivery (normalized per area) is important in high

235 delivery areas except for air pollution removal, which is slightly higher in low delivery areas.

236 This difference is due to the variations of tree cover. For instance, in high delivery class 237 sequestered carbon is about $696 \mathrm{~kg} \mathrm{ha}^{-1}$ and removed pollution is about $6 \mathrm{~g} \mathrm{~m}^{-2}$ (of tree cover).

238 In contrast, trees sequestered about $42 \mathrm{~kg} \mathrm{ha}^{-1}$ of carbon and removed about $7.5 \mathrm{~g} \mathrm{~m}^{-2}$ of air 239 pollutants in low delivery class. However, the total amount of pollutant reduction is fifty times 240 greater in the high delivery class than the low class. This is due to the greater area and greater 241 percentage of tree cover (25\% of high delivery class is covered by trees while cover percentage 242 within low delivery class not exceed $2 \%$ ). Low-delivery areas are typically located in the 243 historic center and the Midwestern area of the city, which is dominated by industrial areas with 244 low tree cover (Fig. 1a). 


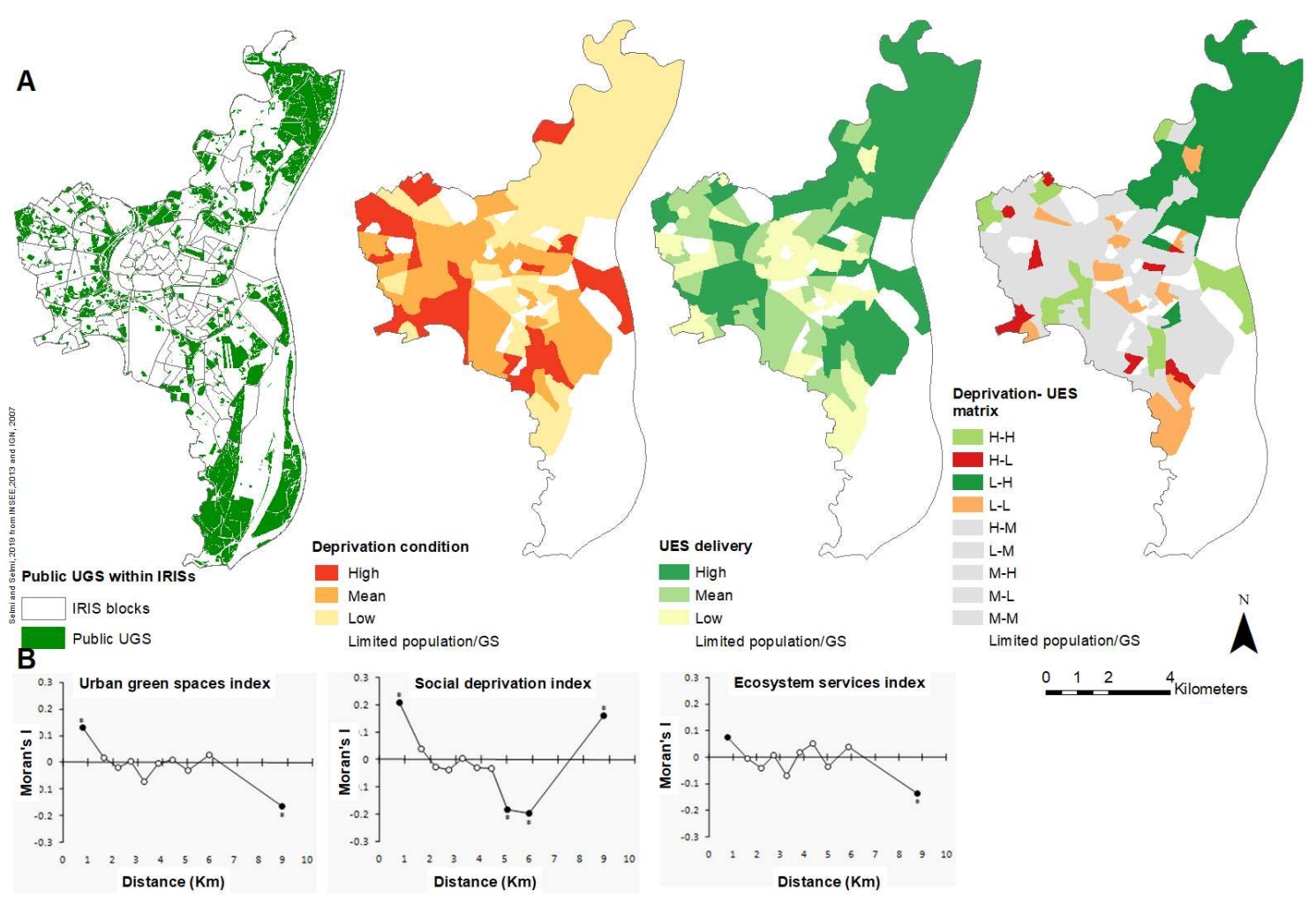

Figure 1. (A) Ecosystem services delivery, deprivation and combined (deprivation-UES) distribution maps within Strasbourg. H-M through L-M were mapped with the same symbol as we want to highlight extreme combinations. (B) Moran's I correlograms of the three indices in the 94 studied IRISs. Significant Moran's I values at the 0.05 level are highlighted in bold. Asterisk-marked symbols represent Moran's I values significant at the Bonferroni corrected level of $0.05 / 10=0.005$

\subsection{Deprivation and UES delivery matrix}

Comparisons of deprivation condition with UES delivery (Fig. 1a, Table 2) show that 9

IRISs are vulnerable (high deprivation and low UES delivery: H-L) where 97\% of its housing is apartment-type and only $1 \%$ of the area is covered by trees. Eleven IRISs are in deprived condition and moderate UES delivery (H-M). These two classes (H-L and H-M) are located in central districts and the extreme western fringe of the city (Fig. 1A). Conversely, 8 IRISs have the northern side of the city where $31 \%$ of the total area was covered by trees. Population across 
the two classes is almost equally distributed with $10 \%$ and $9.8 \%$ of the total population living in vulnerable areas $(\mathrm{H}-\mathrm{L})$ and in areas with great quality of life $(\mathrm{L}-\mathrm{H})$ respectively.

Eight IRISs are considered as highly deprived and high producers of UES (H-H) with $13 \%$ of the total population living in these 8 IRISs. 14 IRISs have a low deprivation condition and low UES production (L-L) where $13 \%$ of total inhabitants of the city is concentrated.

Table 2. Distribution of IRIS across the deprivation-ES delivery matrix. Parentheses in the first row represent the percentage of IRISs and the parentheses in the second row represent the percentage of the population

\begin{tabular}{|c|c|c|c|c|}
\hline Deprivation & Low & Moderate & High & Total \\
\hline Low & $\begin{array}{c}14(32.6) \\
(39.1)\end{array}$ & $\begin{array}{c}20(46.5) \\
(31.6)\end{array}$ & $\begin{array}{c}9(20.9) \\
(29.7)\end{array}$ & 43 \\
\hline Moderate & $\begin{array}{c}11(40.7) \\
(65.7)\end{array}$ & $\begin{array}{c}5(18.5) \\
(13.8)\end{array}$ & $\begin{array}{c}11(40,7) \\
(20.7)\end{array}$ & 27 \\
\hline High & $8(33.3)$ & $8(33.3)$ & $8(33.3)$ & 24 \\
& $(34.7)$ & $(38.7)$ & $(26.6)$ & $\mathbf{2 8}$ \\
\hline Total & $\mathbf{3 3}$ & $\mathbf{3 3}$ & & \\
\hline
\end{tabular}

3.3. Spatial autocorrelation and relationships between social deprivation, green space and UES parameters

Moran's I correlograms show that the social deprivation, UGS, and UES indices exhibit significant spatial autocorrelation (Fig. 1B). Of particular importance is the positive spatial autocorrelation in the first distance class, i.e. pairs of IRISs less than $0.527 \mathrm{~km}$ from each other (social deprivation index: $I=0.207, P<0.001$; UGS index: $I=0.131, P<0.001$; UES index: $I=0.074 ; P=0.043)$. IRISs close to each other show more similar levels of social deprivation, UGS and UES delivery than predicted by a random distribution of these variables, reflecting the 'contagious' nature of these parameters in the studied city.

This significant spatial autocorrelation would suggest that nearby IRISs could not be considered as independent sampling units when investigating the relationships of social deprivation with UGS and UES parameters. This finding is supported by the results of 
regression analyses, which show that models accounting for spatial covariance among observations provide better fit to the data than standard models that assumed independence among model errors, based on AICc and $\mathrm{R}^{2}$ values (see below). These regression models show negative but still non-significant associations of social deprivation with both UGS (non-spatial model: $\mathrm{AICc}=272, \mathrm{R}^{2}=0.1 \% ; \beta \pm \mathrm{SE}=-0.020 \pm 0.104 ; t=-0.193, P=0.8470 ;$ spatial model: $\left.\mathrm{AICc}=237, \mathrm{R}^{2}=33 \% ; \beta \pm \mathrm{SE}=-0.107 \pm 0.103 ; t=-1.043, P=0.3000\right)$ and UES (non-spatial model: $\mathrm{AICc}=277, \mathrm{R}^{2}=0.1 \% ; \beta \pm \mathrm{SE}=-0.034 \pm 0.104 ; t=-0.327, P=0.7450 ;$ spatial model: $\left.\mathrm{AICc}=247, \mathrm{R}^{2}=26 \% ; \beta \pm \mathrm{SE}=-0.099 \pm 0.114 ; t=-0.870, P=0.3870\right)$.

\section{Discussion}

We examined the distribution of UES delivery and whether it is associated with social deprivation condition across census blocks in Strasbourg. Developing a spatial assessment approach at this level is of interest because the majority of UES are produced at the local scale, except for climate regulation which is provided at a larger scale (city, region, country) (Baró et al. 2019). Thus, priorities of decision-making may change by acting on low provision areas and protecting high provision ones. In agreement with Escobedo et al. (2011) and de Groot et al. (2010), we argue that urban green patches are most affected by planning and management decisions at the census block scale. However, the implication of different scales should be considered because the relevance of UES could change among social groups and scales depending on needs and local context. Also, managing urban vegetation and related ecosystem services should be addressed in an integrative way by considering all impacts across temporal, political, economic, and spatial scales (Escobedo et al. 2011, Andersson et al. 2019). Unlike other studies carried out in Australia (Dobbs et al, 2014) and USA (Landry and Chakraborty 2009), our results show no significant relationship between UES delivery and social deprivation. This finding is in line with those previously reported in Barcelona (Baró et 
al. 2019), where no association was found between ES distribution and household income. The explanation of our results may rely on two assumptions. The first one is related to the fact that our analysis was conducted on public green spaces where planting and managing decisions are made regardless of the socioeconomic status of the neighborhood. This is in line with findings of Kuras et al. (2020) that suggest that neutral relationship between socioeconomic status and biodiversity, in general, occurs in public land uses. This raises the question whether local policies are not interested in establishing a participatory approach or the residents do not feel concerned by planting strategies of their neighborhood. More investigations are needed to understand interactions between planners, managers and citizens and how they influence greening decisions. The second potential explanation could be a possible difference in the speed of change of green spaces compared to the socioeconomic situation of the population concerned. Indeed, the spatial distribution of green spaces is not likely to evolve at the same speed as the socioeconomic parameters of the population, as has previously been highlighted in a New Zealand study on the relationship between green spaces and public health (Richardson et al. 2010). mutation in Strasbourg at the mid and long terms, namely the gentrification (Gerber 1999; Blanchard 2019). Municipal investments want to make the city uniform in terms of quality of life. This uniformity can make it greener, but may increase property values which can displace socioeconomically disadvantaged classes and exclude them from access to amenities while in Barcelona, it was shown that gentrification took place in old industrial and desirable 
Studying this process in Strasbourg will provide relevant information about the impact of planning strategies (including greening strategies) on creating (or not) new inequities.

The trend of negative association between ES delivery and social deprivation in Strasbourg city may be visible over a more extended period, with taking into account the consequences of gentrification and interactions between the city and surrounding villages. Further research should investigate shifts in historical expansion of the city, population demography, socioeconomic status across neighborhoods to better understand the link between UES delivery and deprivation conditions over time. This research could help substantiate the idea of Pickett et al. (2008), who argued that the ecological dynamic within a city is slower than the social dynamics. Thus, the ecological structure of a particular neighborhood may reflect a previous social structure, not the existing one.

Our approach not only demonstrates the absence of a relationship between ES delivery and social deprivation, but also detects their spatial distribution including vulnerable areas (i.e. low ES provision and high social deprivation) and advantaged areas (i.e. high ES provision and low social deprivation). In our case, it is also important to notice that descriptive analyses show that the number of deprived neighborhoods with high UES is not negligible, which is consistent with findings in other European cities like Porto (Graça et al. 2017), Barcelona (Baró et al. 2019) and Paris (Cohen et al. 2012). This neutral relationship may be explained by the planning trends that facilitate greening actions and thus, UES provision across time (Kuras et al. 2020). In Strasbourg, major urban projects were carried out in the urban fringe between 1950 and 1970 that represented the core of the social housing urban fabric of the city. At that time, those neighborhoods were designed toward a predefined percentage of 10 to $40 \%$ of green spaces (POS 1979), which explains the observed high level of UES delivery. Consequently, other mechanisms like urban policies and landscape structure seem to have an impact on UES 
delivery and should be studied to identify factors that spatially influence ecosystem services distribution.

As demonstrated by other findings (Dobbs et al. 2014; Wilkerson et al. 2018), studying the link between landscape structure and UES distribution gives insights on the consequences of planning strategies on ecosystem services provision. These strategies, which have to be sustainable, should include actions to improve the quantity, the distribution and the connection between green spaces to equitably increase ecosystem services provision and hence to ensure a balance between social and ecological health within the city.

UGS within socially-deprived neighborhoods where high population density occurs may be faced with over-use. In addition to maintaining current UES potential, management planning in those neighborhoods could focus on environmental quality drivers like recreational facilities, diversified vegetation features, and maintenance types. Moreover, daily experiences and perceptions of users could be taken into account to help green spaces services meet resident needs (Hoffimann et al. 2017). Improved residents' awareness about nearby UGS and its services could encourage support for its development and maintenance. It could also help build community cohesion by recognizing local community power and expertise, which facilitates the involvement of residents into the local decision-making process (Lovell and Taylor 2013). High and moderate UES provisions were generally located within the green belt of the city that is entirely included within the so-called "Urban Natural Park". This park resides within the deprived districts "Elsau", "Koenigshoffen" and "Montagne verte" and surrounds the central core of the city. One issue of concern is that $20 \%$ of the green belt could be built in the future. Protecting this resource by reducing development can help preserve the current UES flow. Enhancing the connectivity of green spaces within the green belt could also connect neighborhoods of different socioeconomic levels, improve social mixing, and provide equitable access to UES among different social categories. New urban projects in proposed development 
areas should address the gentrification risk to ensure equal opportunities to a healthy environment among various socioeconomic classes. Urban policies could go beyond distributional justice to procedural justice to involve different social classes in making connections among neighborhoods.

Spatial results of areas with high or low UES delivery could be crossed with the zoning of the local urbanism plan (PLU) to better inform on the risk of environmental degradation if future development occurs. For instance, few high UES provision patches were located within areas assigned to future urbanization. In this case, strategies to maintain UES provision in these areas could be investigated (Baró et al. 2016). Conversely, areas assigned to urbanization with low UES provision could represent an opportunity to create sustainable urban projects that support social mix, meet social needs, and enhance UES. According to existing literature, addressing these issues is still challenging for urban renewal policies (Anguelovski and Martinez Alier 2014; Chen and Yonh Hu 2015).

Studying UES from the EJ perspective may produce information stating an equitable distribution of services provided by UGS. While approaches that can holistically quantify UES are needed (Dobbs et al. 2014; Riley and Gardiner 2019), it may also be of interest to analyze only the most easily measured variable, most relevant for local policies, or the most needed by citizens and use it as a proxy for all UES only if a strong correlation is found between them, which is our case. Although the correlation is demonstrated for the three quantified services, the link between these services and others such as cultural services or temperature reduction services should be explored to have a relatively global vision of the potential of vegetation to produce benefits for the population. Furthermore, decision-makers could go beyond characterizing the non-significant disparity in UES distribution and move into identifying vulnerable neighborhoods and establishing priorities. 
In sum, our study does not reveal a direct relationship between socioeconomic status and the distribution of UES provision in Strasbourg city. To have a complete vision of UES and meet local needs, studies could investigate the impact of socioeconomic factors on the demand of UES and the relationship between supply and demand of UES (Baró et al. 2015; Larondelle and Lauf 2016). Wilkerson et al. (2018) report that socially advantaged population prioritizes recreational services instead of regulation services or production services. Given our results, does social deprivation mean high demand for UES in Strasbourg city? How does socioeconomic status influence perception and behaviors?

\section{Research limitations}

The estimation of UES production by i-Tree Eco was analyzed by land-use classes and disaggregated into the IRIS level. This limitation could be overcome with an increased sampling that would provide enough plot data to analyze results by IRIS. Multiple models run with locally specific weather, and pollution data could increase local specificity of the analyses, but these data are currently lacking.

This study focused on the IRIS level with varying area. Variables were converted to density, proportion, and ratios for all IRISs to normalize the area. Dividing the city into equal spatial units could be interesting to reduce the sensitivity of results to IRISs areas. A multi-scale study could be more effective to understand different synergies between UES and to connect local and regional actors.

Only tree cover and green spaces densities were analyzed. However, other factors could influence the provision of UES such as age, diameter, green spaces area, and the total number of trees (Dobbs et al. 2014). Further research is needed to understand better interactions between structural variables, ES flow and socioeconomic status. Similarly, only regulation services were examined in this study. These services mainly depend on tree cover as it presents the ecological 
reservoir that ensures their production. However, the distribution of other categories of services such as cultural services may not be associated with tree cover but rather with perception, use, accessibility, etc. (Riley and Gardiner 2019).

In this study only public green spaces have been considered. However, private green spaces, such as private gardens, cemeteries, allotment gardens and schools' gardens, may also contribute to total UES provision in the city. Although these private green spaces are not easily controlled by urban managers, their connection with public spaces to benefit from their ecological potential would be an interesting path to explore through the environmental justice framework. In addition, it would also be interesting to verify whether there is compensation between the UES produced by private spaces and the UES produced by public green spaces (i.e. verify whether the neighborhoods with low public green spaces and low ES provision have more access to private gardens and their associated ES).

Finally, the main challenge of this study was the combination of socioeconomic and ecological indicators. Composite indicators were created and classified into low, moderate, and high clusters according to mean and standard deviation values. The aim was to simplify the information, but it would be interesting to study the impact of each socioeconomic indicator on each UES. Extensive research is also needed to define a mapping method that is transferable and easy for decision-makers to use.

\section{Conclusion}

This study used a spatially explicit approach to visualize the distribution of UES across socioeconomic conditions in Strasbourg, France. Using tools that connect UES to a social context is useful to identify priority areas where enhancing UES and social justice are needed. Urban policies could prioritize areas with high deprivation and low UES provision by defining 
strategies that improve the quality and/or the number of green spaces, optimize UES and foster the connection between population and local green spaces. Distributive environmental justice studies could be followed by investigations of interactional and procedural justice that aim to highlight the personal experiences of populations and their involvement in the decision-making process. Comparing results with perceived access to UES according to the socioeconomic condition of the population can help to identify the well-being demand in the city. A key challenge of this work is to integrate outcomes of UES mapping into decision-making processes that support future urban planning strategies and are consistent with social needs and environmental restoration of the city. Considering environmental justice patterns associated with UES in current urban policies may impact the interactions between society and seminatural ecosystems within the city in the future.

\section{Acknowledgements}

This work was supported by “'Institution de la Recherche et de l'Enseignement Supérieur Agricoles (IRESA-Tunisia), 'Zone Atelier Environnementale Strasbourg' (ZAEU) and “'Eurométropole de Strasbourg”, (EMS).

\section{References}

ADEUS. 2018. Plan Climat Air Energie territorial de l'Eurométropole de Strasbourg. Diagnostic et evolution de la situation Climat Air Energie, Strasbourg, France.

Agyeman, J., R. D. Bullard, and B. Evans. 2002. Exploring the Nexus: Bringing Together Sustainability, Environmental Justice and Equity. Space and Polity 6: 77-90. doi:10.1080/13562570220137907.

Amini Parsa, V., E. Salehi, A. R. Yavari, and P. M. van Bodegom. 2019. An improved method for assessing mismatches between supply and demand in urban regulating ecosystem services: A case study in Tabriz, Iran. Edited by Ali Kharrazi. PLOS ONE 14: e0220750. doi:10.1371/journal.pone.0220750. 
Andersson, E., J. Langemeyer, S. Borgström, T. McPhearson, D. Haase, J. Kronenberg, D. N. Barton, M. Davis, et al. 2019. Enabling Green and Blue Infrastructure to Improve Contributions to Human Well-Being and Equity in Urban Systems. BioScience 69: 566574. doi:10.1093/biosci/biz058.

Anguelovski, I., J. J. T. Connolly, L. Masip, and H. Pearsall. 2018. Assessing green gentrification in historically disenfranchised neighborhoods: a longitudinal and spatial analysis of Barcelona. Urban Geography 39: 458-491. doi:10.1080/02723638.2017.1349987.

Anguelovski, I., and J. Martínez Alier. 2014. The 'Environmentalism of the Poor' revisited: Territory and place in disconnected glocal struggles. Ecological Economics 102: 167-176. doi:10.1016/j.ecolecon.2014.04.005.

Atmo GRAND-EST, 2018. Bilan de la qualité de l'air. 2018. Retrieved 10 March, 2020, from http://www.atmo-grandest.eu/sites/prod/files/2019-12/BQA2018_indice2.pdf

Baró, F., D. Haase, E. Gómez-Baggethun, and N. Frantzeskaki. 2015. Mismatches between ecosystem services supply and demand in urban areas: A quantitative assessment in five European cities. Ecological Indicators 55: 146-158. doi:10.1016/j.ecolind.2015.03.013.

Baró, F., A. Calderón-Argelich, J. Langemeyer, and J. J. T. Connolly. 2019. Under one canopy? Assessing the distributional environmental justice implications of street tree benefits in Barcelona. Environ Sci Policy 102: 54-64. doi:10.1016/j.envsci.2019.08.016.

Baró, F., I. Palomo, G. Zulian, P. Vizcaino, D. Haase, and E. Gómez-Baggethun. 2016. Mapping ecosystem service capacity, flow and demand for landscape and urban planning: A case study in the Barcelona metropolitan region. Land Use Policy 57: 405-417. doi:10.1016/j.landusepol.2016.06.006.

Blanchard, N. Etude du phénomène d'embourgeoisement à l'œuvre dans un quartier en mutation à Strasbourg: 19. 
Boone, C. G., and M. Fragkias, ed. 2013. Urbanization and Sustainability. Dordrecht: Springer Netherlands. doi:10.1007/978-94-007-5666-3.

Boyce, J. K., K. Zwickl, and M. Ash. 2016. Measuring environmental inequality. Ecological Economics 124: 114-123. doi:10.1016/j.ecolecon.2016.01.014.

Brown, A., A. Dayal, and C. Rumbaitis Del Rio. 2012. From practice to theory: emerging lessons from Asia for building urban climate change resilience. Environment and Urbanization 24: 531-556. doi:10.1177/0956247812456490.

Chen, W. Y., and F. Z. Y. Hu. 2015. Producing nature for public: Land-based urbanization and provision of public green spaces in China. Applied Geography 58: 32-40. doi:10.1016/j.apgeog.2015.01.007.

Cohen, M., R. Baudoin, M. Palibrk, N. Persyn, and C. Rhein. 2012. Urban biodiversity and social inequalities in built-up cities: New evidences, next questions. The example of Paris, France. Landscape and Urban Planning 106: 277-287. doi:10.1016/j.landurbplan.2012.03.007.

Cressie, N.A.C. 1993. Statistics for spatial data. Wiley-Interscience Publications, New York.

de Groot, R. S., R. Alkemade, L. Braat, L. Hein, and L. Willemen. 2010. Challenges in integrating the concept of ecosystem services and values in landscape planning, management and decision making. Ecological Complexity 7: 260-272. doi:10.1016/j.ecocom.2009.10.006.

Dobbs, C., D. Kendal, and C. R. Nitschke. 2014. Multiple ecosystem services and disservices of the urban forest establishing their connections with landscape structure and sociodemographics. Ecological Indicators 43: 44-55. doi:10.1016/j.ecolind.2014.02.007.

EFESE. 2018. Les écosystèmes urbains. Retrieved 5 April, 2019, from https://www.ecologie.gouv.fr/levaluation-francaise-desecosystemes-et-des-servicesecosystemiques. 
Ernstson, H., S. Barthel, E. Andersson, and S. T. Borgström. 2010. Scale-crossing brokers and network governance of urban ecosystem services: The case of stockholm. Ecology and Society 15. doi:10.5751/ES-03692-150428.

Escobedo, F. J., N. Clerici, C. L. Staudhammer, and G. T. Corzo. 2015. Socio-ecological dynamics and inequality in Bogotá, Colombia's public urban forests and their ecosystem services. Urban Forestry and Urban Greening 14: 1040-1053. doi:10.1016/j.ufug.2015.09.011.

Escobedo, F. J., V. Giannico, C. Y. Jim, G. Sanesi, and R. Lafortezza. 2019. Urban forests, ecosystem services, green infrastructure and nature-based solutions: Nexus or evolving metaphors? Urban Forestry \& Urban Greening 37. Green Infrastructures: Nature Based Solutions for Sustainable and Resilient Cities: 3-12. doi:10.1016/j.ufug.2018.02.011.

Escobedo, F. J., T. Kroeger, and J. E. Wagner. 2011. Urban forests and pollution mitigation: Analyzing ecosystem services and disservices. Environmental Pollution 159. Selected Papers from the Conference Urban Environmental Pollution: Overcoming Obstacles to Sustainability and Quality of Life (UEP2010), 20-23 June 2010, Boston, USA: 20782087. doi:10.1016/j.envpol.2011.01.010.

Faburel, G., and S. Gueymard. 2008. Inégalités environnementales en région Île-de-France : le rôle structurant des facteurs négatifs de l'environnement et des choix politiques afférents. Espace populations sociétés. Space populations societies: 159-172. doi:10.4000/eps.2477.

Fisher, B., R. K. Turner, and P. Morling. 2009. Defining and classifying ecosystem services for decision making. Ecological Economics 68: 643-653. doi:10.1016/j.ecolecon.2008.09.014.

Gerber, P. 1999. Processus de gentrification et demande sociale citadine. Exemple du centreville de Strasbourg. Revue Géographique de l'Est 39. 
Graça, M. S., J. F. Gonçalves, P. J. M. Alves, D. J. Nowak, R. Hoehn, A. Ellis, P. FarinhaMarques, and M. Cunha. 2017. Assessing mismatches in ecosystem services proficiency across the urban fabric of Porto (Portugal): The influence of structural and socioeconomic variables. Ecosystem Services 23: 82-93. doi:10.1016/j.ecoser.2016.11.015.

Graça, M., P. Alves, J. Gonçalves, D. J. Nowak, R. Hoehn, P. Farinha-Marques, and M. Cunha. 2018. Assessing how green space types affect ecosystem services delivery in Porto, Portugal. Landscape and Urban Planning 170: 195-208. doi:10.1016/j.landurbplan.2017.10.007.

Greenberg, M., and M. Cidon. 1997. Broadening the definition of environmental equity: A framework for states and local governments. Population Research and Policy Review 16: 397-413. doi:10.1023/A:1005702430607.

Grove, J. M., A. R. Troy, J. P. M. O’Neil-Dunne, W. R. Burch, M. L. Cadenasso, and S. T. A. Pickett. 2006. Characterization of Households and its Implications for the Vegetation of Urban Ecosystems. Ecosystems 9: 578-597. doi:10.1007/s10021-006-0116-Z.

Havard, S., S. Deguen, J. Bodin, K. Louis, O. Laurent, and D. Bard. 2008. A small-area index of socioeconomic deprivation to capture health inequalities in France. Social Science \& Medicine 67: 2007-2016. doi:10.1016/j.socscimed.2008.09.031.

Heynen, N., H. A. Perkins, and P. Roy. 2006. The Political Ecology of Uneven Urban Green Space: The Impact of Political Economy on Race and Ethnicity in Producing Environmental Inequality in Milwaukee. Urban Affairs Review 42: 3-25. doi:10.1177/1078087406290729.

Hoffimann, E., H. Barros, and A. Ribeiro. 2017. Socioeconomic Inequalities in Green Space Quality and Accessibility_Evidence from a Southern European City. International Journal of Environmental Research and Public Health 14: 916. doi:10.3390/ijerph14080916. 
INSEE. 2016. Recensement de la population. 2013. Retrieved 1 January, 2019, from https://insee.fr/fr/accueil

i-Tree Eco User's Manual. 2013. Retrieved 23 January, 2013, from https://www.itreetools.org/resources/manuals/EcoManualv5.pdf http://www.itreetools.org/resources/archives.

Jenerette, G. D., S. L. Harlan, W. L. Stefanov, and C. A. Martin. 2011. Ecosystem services and urban heat riskscape moderation: water, green spaces, and social inequality in Phoenix, USA. Ecol Appl 21: 2637-2651.

Jensen, R., J. Gatrell, J. Boulton, and B. Harper. 2005. Using Remote Sensing and Geographic Information Systems to Study Urban Quality of Life and Urban Forest Amenities. Ecology and Society 9. doi:10.5751/ES-01201-090505.

Kremer, P., Z. Hamstead, D. Haase, T. McPhearson, N. Frantzeskaki, E. Andersson, N. Kabisch, N. Larondelle, et al. 2016. Key insights for the future of urban ecosystem services research. Ecology and Society 21.

Kruize, H., P. P. J. Driessen, P. Glasbergen, and K. van Egmond. 2007. Environmental Equity and the Role of Public Policy: Experiences in the Rijnmond Region. Environmental Management 40: 578-595. doi:10.1007/s00267-005-0378-9.

Kuras, E. R., P. S. Warren, J. A. Zinda, M. F. J. Aronson, S. Cilliers, M. A. Goddard, C. H. Nilon, and R. Winkler. 2020. Urban socioeconomic inequality and biodiversity often converge, but not always: A global meta-analysis. Landscape and Urban Planning 198: 103799. doi:10.1016/j.landurbplan.2020.103799.

Lakes, T., M. Brückner, and A. Krämer. 2014. Development of an environmental justice index to determine socio-economic disparities of noise pollution and green space in residential areas in \{Berlin\}. Journal of Environmental Planning and Management 57: 538-556. doi:10.1080/09640568.2012.755461. 
Landry, S. M., and J. Chakraborty. 2009. Street Trees and Equity: Evaluating the Spatial Distribution of an Urban Amenity. Environment and Planning A: Economy and Space 41: 2651-2670. doi:10.1068/a41236.

Larondelle, N., and S. Lauf. 2016. Balancing demand and supply of multiple urban ecosystem services on different spatial scales. Ecosystem Services 22: 18-31. doi:10.1016/j.ecoser.2016.09.008.

Legendre, P., and L. Legendre. 1998. Numerical Ecology, Volume 24 - 2nd Edition.

Lovell, S. T., and J. R. Taylor. 2013. Supplying urban ecosystem services through multifunctional green infrastructure in the United States. Landscape Ecology 28: 14471463. doi:10.1007/s10980-013-9912-y.

Martinuzzi, S., O. M. Ramos-González, T. A. Muñoz-Erickson, D. H. Locke, A. E. Lugo, and V. C. Radeloff. 2018. Vegetation cover in relation to socioeconomic factors in a tropical city assessed from sub-meter resolution imagery. Ecological Applications 28: 681-693. doi:10.1002/eap.1673.

McPhearson, T., P. Kremer, and Z. A. Hamstead. 2013. Mapping ecosystem services in New York City: Applying a social-ecological approach in urban vacant land. Ecosystem Services 5: 11-26. doi:10.1016/j.ecoser.2013.06.005.

Nowak, D.J., D.E. Crane, J.C. Stevens, R.E. Hoehn, J.T. Walton, and J. Bond. 2008. A groundbased method of assessing urban forest structure and ecosystem services. Arboriculture and Urban Forestry 34: 347-358.

Pham, T.-T.-H., P. Apparicio, A.-M. Séguin, S. Landry, and M. Gagnon. 2012. Spatial distribution of vegetation in Montreal: An uneven distribution or environmental inequity? Landscape and Urban Planning 107: 214-224. doi:10.1016/j.landurbplan.2012.06.002.

Pickett, S. T. A., M. L. Cadenasso, J. M. Grove, P. M. Groffman, L. E. Band, C. G. Boone, W. R. Burch, C. S. B. Grimmond, et al. 2008. Beyond Urban Legends: An Emerging 
Framework of Urban Ecology, as Illustrated by the Baltimore Ecosystem Study. BioScience 58: 139-150. doi:10.1641/B580208.

Raddatz, L., and J. Mennis. 2013. Environmental Justice in Hamburg, Germany. The Professional Geographer 65: 495-511. doi:10.1080/00330124.2012.700500.

Rangel, T. F. L. V. B., J. A. F. Diniz-Filho, and L. M. Bini. 2006. Towards an integrated computational tool for spatial analysis in macroecology and biogeography. Global Ecology and Biogeography 15: 321-327. doi:10.1111/j.1466-822X.2006.00237.x.

Richardson, E., J. Pearce, R. Mitchell, P. Day, and S. Kingham. 2010. The association between green space and cause-specific mortality in urban New Zealand: an ecological analysis of green space utility. BMC Public Health 10: 240. doi:10.1186/1471-2458-10-240.

Riley, C. B., and M. M. Gardiner. 2020. Examining the distributional equity of urban tree canopy cover and ecosystem services across United \{States\} cities. PLOS ONE 15: e0228499. doi:10.1371/journal.pone.0228499.

Schüle, S. A., L. K. Hilz, S. Dreger, and G. Bolte. 2019. Social Inequalities in Environmental Resources of Green and Blue Spaces: A Review of Evidence in the WHO European Region. Int J Environ Res Public Health 16. doi:10.3390/ijerph16071216.

Selmi, W., C. Weber, E. Rivière, N. Blond, L. Mehdi, and D. Nowak. 2016. Air pollution removal by trees in public green spaces in Strasbourg city, France. Urban Forestry and Urban Greening 17. doi:10.1016/j.ufug.2016.04.010.

Sievers-Glotzbach, S. 2013. Ecosystem Services and Distributive Justice: Considering Access Rights to Ecosystem Services in Theories of Distributive Justice. Ethics, Policy \& Environment 16: 162-176. doi:10.1080/21550085.2013.801203.

Srang-iam, W. Planting Trees for Sustainability? A Climate Justice Perspective on Green Agriculture in Thailand: 22. 
Tratalos, J., R. A. Fuller, P. H. Warren, R. G. Davies, and K. J. Gaston. 2007. Urban form, biodiversity potential and ecosystem services. Landscape and Urban Planning 83: 308317. doi:10.1016/j.landurbplan.2007.05.003.

Vyas, S., and L. Kumaranayake. 2006. Constructing socio-economic status indices: How to use principal components analysis. Health Policy and Planning 21: 459-468.

Wilkerson, M. L., M. G. E. Mitchell, D. Shanahan, K. A. Wilson, C. D. Ives, C. E. Lovelock, and J. R. Rhodes. 2018. The role of socio-economic factors in planning and managing urban ecosystem services. Ecosystem Services 31: 102-110.

Yang, J., Y. Guan, J. (Cecilia) Xia, C. Jin, and X. Li. 2018. Spatiotemporal variation characteristics of green space ecosystem service value at urban fringes: $\{A\}$ case study on Ganjingzi District in Dalian, China. Science of The Total Environment 639: 1453-1461. doi:10.1016/j.scitotenv.2018.05.253.

Zhao, C., and H. A. Sander. 2015. Quantifying and Mapping the Supply of and Demand for Carbon Storage and Sequestration Service from Urban Trees. PLoS One 10. doi:10.1371/journal.pone.0136392. 